\title{
Thoracic and respirable particle definitions for human health risk assessment
}

\author{
James S Brown ${ }^{1 *}$, Terry Gordon ${ }^{2}$, Owen Price ${ }^{3}$ and Bahman Asgharian ${ }^{4}$
}

\begin{abstract}
Background: Particle size-selective sampling refers to the collection of particles of varying sizes that potentially reach and adversely affect specific regions of the respiratory tract. Thoracic and respirable fractions are defined as the fraction of inhaled particles capable of passing beyond the larynx and ciliated airways, respectively, during inhalation. In an attempt to afford greater protection to exposed individuals, current size-selective sampling criteria overestimate the population means of particle penetration into regions of the lower respiratory tract. The purpose of our analyses was to provide estimates of the thoracic and respirable fractions for adults and children during typical activities with both nasal and oral inhalation, that may be used in the design of experimental studies and interpretation of health effects evidence.
\end{abstract}

Methods: We estimated the fraction of inhaled particles (0.5-20 $\mu \mathrm{m}$ aerodynamic diameter) penetrating beyond the larynx (based on experimental data) and ciliated airways (based on a mathematical model) for an adult male, adult female, and a $10 \mathrm{yr}$ old child during typical daily activities and breathing patterns.

Results: Our estimates show less penetration of coarse particulate matter into the thoracic and gas exchange regions of the respiratory tract than current size-selective criteria. Of the parameters we evaluated, particle penetration into the lower respiratory tract was most dependent on route of breathing. For typical activity levels and breathing habits, we estimated a 50\% cut-size for the thoracic fraction at an aerodynamic diameter of around $3 \mu \mathrm{m}$ in adults and $5 \mu \mathrm{m}$ in children, whereas current ambient and occupational criteria suggest a 50\% cut-size of $10 \mu \mathrm{m}$.

Conclusions: By design, current size-selective sample criteria overestimate the mass of particles generally expected to penetrate into the lower respiratory tract to provide protection for individuals who may breathe orally. We provide estimates of thoracic and respirable fractions for a variety of breathing habits and activities that may benefit the design of experimental studies and interpretation of particle size-specific health effects.

Keywords: Size-selective sampling, Fine and coarse particles

\section{Background}

It has long been recognized that the regional pattern of particle deposition in the respiratory tract affects the pathogenic potential of inhaled aerosols. For example, Morgan [1] concluded that respirable dusts likely caused pneumoconiosis and silicosis in coal miners, whereas a larger size fraction caused bronchitis and obstructive changes in pulmonary function. Sampling the total air concentration of particulate matter (PM) provides a crude estimate of exposure that may not correlate with observed health

\footnotetext{
* Correspondence: Brown.James@epa.gov

${ }^{1}$ National Center for Environmental Assessment, U.S. Environmental Protection Agency, MD B243-01, Research Triangle Park, Raleigh, NC 27711, USA

Full list of author information is available at the end of the article
}

effects if the risk is associated only with those particles that may enter the thorax or penetrate beyond the ciliated airways. The concept of size-selective particle sampling has been employed as a means for effectively sampling the particle sizes associated with specific pathologic outcomes (e.g., the respirable fraction with parenchymal disease). If an environmentally or occupationally related particle is recognized to only affect the gas-exchange region of the lung, then a sampling strategy that only collects the respirable fraction of airborne PM is preferable to sampling total suspended particulate (TSP) or the thoracic fraction.

The human respiratory tract can be divided into three main regions based on size, structure, and function, namely, the head, tracheobronchial region (also known as

\section{Biomed Central}

(c) 2013 Brown et al.; licensee BioMed Central Ltd. This is an Open Access article distributed under the terms of the Creative Commons Attribution License (http://creativecommons.org/licenses/by/2.0), which permits unrestricted use, distribution, and reproduction in any medium, provided the original work is properly cited. 
the conducting airways), and the gas-exchange region (also known as the parenchymal, alveolar, or pulmonary) region. Size-selective sampling is intended to help discern the amount of aerosol expected to be available for deposition in a region. Most sampling conventions have been defined in terms of particle penetration into respiratory regions rather than the expected particle deposition or dose to regions. Specific definitions used herein, adopted from the European Committee for Standardization (CEN), are [2]:

- Inhalable fraction - the mass fraction of total airborne particles which is inhaled through the nose and mouth.

- Extrathoracic fraction - the mass fraction of inhaled particles failing to penetrate beyond the larynx.

- Thoracic fraction - the mass fraction of inhaled particles penetrating beyond the larynx.

- Respirable fraction - the mass fraction of inhaled particles penetrating to the unciliated airways. ${ }^{\text {a }}$

The above definitions are stated in terms of a mass fraction. Relative to total airborne particles, the particle size having $50 \%$ penetration for the thoracic and respirable fractions are $10 \mu \mathrm{m}$ and $4.0 \mu \mathrm{m}$ (all particle sizes are aerodynamic diameter unless expressed otherwise), respectively $[2,3]$. These criteria were specifically developed for workplace atmospheres. Since particles must generally become deposited to exert biological effects, these conventions, based on regional exposure (i.e., particles penetrating into a region of the respiratory tract), are conservative by design in that they overestimate the amount of inhaled material that becomes deposited and thereby available to induce an effect.

In 1985, the American Conference of Governmental Industrial Hygienists (ACGIH) recommended particle sizeselective sampling in setting threshold limit values for occupational exposures [4]. ${ }^{\mathrm{b}}$ The ACGIH specifically considered a reference worker (weight, $70 \mathrm{~kg}$; height, $175 \mathrm{~cm}$ ) breathing orally while engaged in light activity (minute ventilation, 21.75 liters/min). Criteria were established for Inspirable (now Inhalable), Thoracic, and Respirable Particulate Mass that were intended to be protective against materials that were considered hazardous when deposited anywhere in the respiratory tract, anywhere within the lungs, and in the gas-exchange region, respectively. These criteria were based on exposure of a respiratory tract region (based on particle penetration into that region), not particle deposition in a respiratory tract region. The ACGIH committee recognized uncertainty related to individual biological variability in respiratory health status, breathing patterns (rate and route), and airways structure as well as differences in work rates, all of which can cause differences in inhaled aerosol deposition and dose. Facing these uncertainties, the committee afforded extra protection to exposed workers by over representing the true penetration of particles into regions of the respiratory tract as illustrated in Figure 1 [4].

Size-selective sampling has also been employed by the U. S. Environmental Protection Agency (EPA) in setting the national ambient air quality standards (NAAQS) for particulate matter (PM). In 1987, the EPA changed the indicator for PM from TSP (effectively an aerodynamic cut-size varying from 25 to $40 \mu \mathrm{m}$, depending on wind speed and direction) to $\mathrm{PM}_{10}$ (particles with a nominal mean aerodynamic diameter $\leq 10 \mu \mathrm{m}$ ) [8]. Consistent in concept with the ACGIH thoracic particle fraction, $\mathrm{PM}_{10}$ delineates a subset of inhalable particles (referred to as thoracic particles) that are thought small enough to penetrate to the thoracic region (including the tracheobronchial and alveolar regions) of the respiratory tract. ${ }^{\mathrm{C}}$ In 1997 , the EPA extended size-selective sampling to include fine particles indicated by $\mathrm{PM}_{2.5}$ (particles with a nominal mean aerodynamic

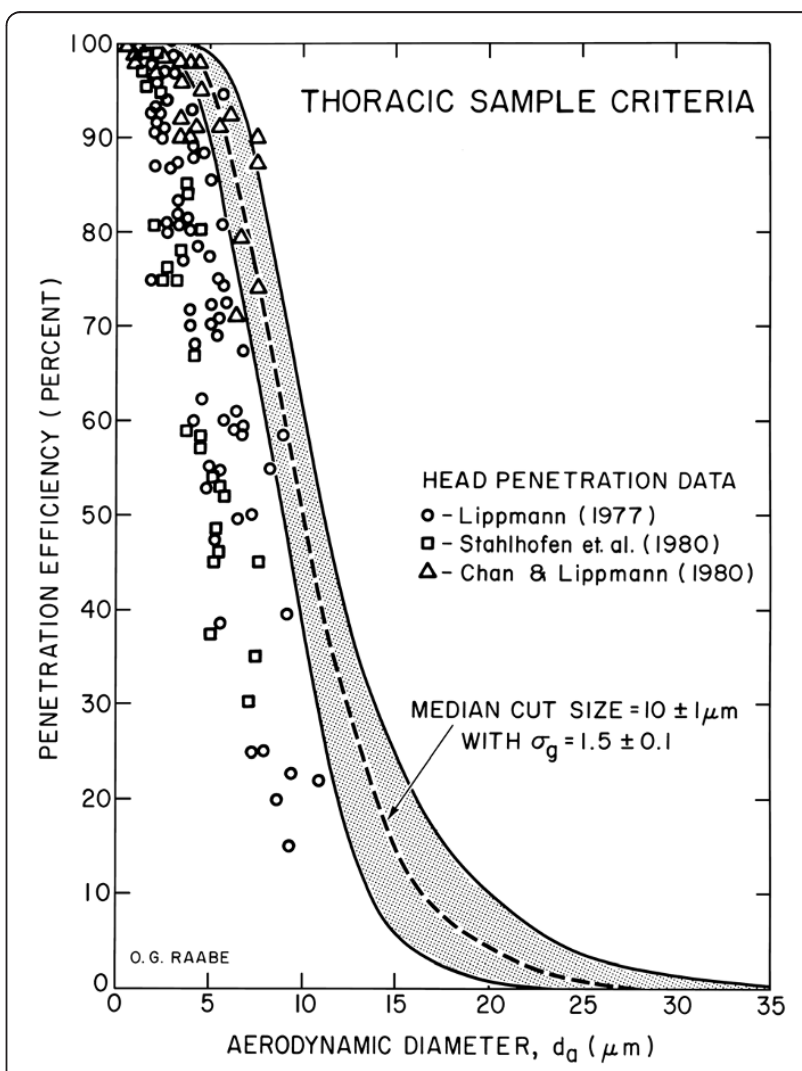

Figure 1 Thoracic particulate mass fraction criteria (relative to total airborne particles) for size-selective sampling. Individual data points are observed human head penetration efficiency during oral inhalation for an inspiratory flow rate of $43.5 \mathrm{~L} / \mathrm{min}$, i.e., light exercise [5-7]. As stated by ACGIH [3], the sampling criterion is offset to the right of experimental data to overestimate the amount of exposure to the lower respiratory tract, i.e., the lungs, and correspondingly to provide a greater level of protection for exposed workers. From $\mathrm{ACGIH}{ }^{\circledR}$, Particle Size-Selective Sampling in the Workplace, Report of the ACGIH ${ }^{\circledR}$ Technical Committee on Air Sampling Procedures. Copyright 1985. Reprinted with permission. Courtesy: Dr. Otto G. Raabe. 
diameter $\leq 2.5 \mu \mathrm{m}$ ) and retained $\mathrm{PM}_{10}$ as the indicator for thoracic coarse particles [9]. The selection of $\mathrm{PM}_{2.5}$ by the EPA was mainly to delineate the atmospheric fine (combustion derived, aggregates, acid condensates, secondary aerosols) and coarse (crustal, soil-derived dusts) PM modes and for consistency with community epidemiologic health studies reporting various health effects associated with $\mathrm{PM}_{2.5}$. With consideration to the PM NAAQS, Miller et al. [10] also specifically recommended a particle size cut-point of $\leq$ $2.5 \mu \mathrm{m}$ as an indicator for fine PM based on consideration of particle penetration into the gas-exchange region and the delineation of the fine and coarse particle modes.

Most recently, the International Organization for Standardization (ISO) has released recommendations for sampling conventions based on particle deposition (rather than exposure) in adult males and females engaged in activities of sitting, light exercise and heavy exercise as specified in Table 1 [11]. The ISO estimates of deposition were determined using the International Commission on Radiological Protection (ICRP) human respiratory tract model [12]. These new ISO conventions [11] are not considered further herein as current sampling conventions for occupational and non-occupational settings remain dependent on the probability of particle penetration rather than deposition in specific regions of the respiratory tract.

Conceptually, size-selective sampling better characterizes PM exposure to regions of the respiratory tract and thereby affords more appropriate avenues for protection of exposed populations than TSP. Such a simple concept is not, however, without ambiguity in definitions and debate over appropriate sampling approaches. For example, the definition for the thoracic fraction specifies particles "penetrating

Table 1 Ventilatory and activity patterns for adult males, adult females, and a ten year-old child

\begin{tabular}{|c|c|c|c|c|c|}
\hline & & Sleeping & Sitting & $\begin{array}{r}\text { Light } \\
\text { Exercise }\end{array}$ & $\begin{array}{r}\text { Heavy } \\
\text { Exercise }\end{array}$ \\
\hline Adult Male & $V_{T}(m L)$ & 625 & 750 & 1250 & 1920 \\
\hline \multirow[t]{3}{*}{ Sedentary worker } & $f\left(m^{-1}\right)$ & 12 & 12 & 20 & 26 \\
\hline & $\mathrm{t}(\mathrm{hr})$ & 8.5 & 5.5 & 9.75 & 0.25 \\
\hline & $V_{\text {daily }}(L /$ day $)$ & 3825 & 2970 & 14625 & 749 \\
\hline Adult Female & $V_{T}(m L)$ & 444 & 464 & 992 & 1364 \\
\hline \multirow[t]{3}{*}{ Sedentary worker } & $f\left(m^{-1}\right)$ & 12 & 14 & 21 & 33 \\
\hline & $\mathrm{t}(\mathrm{hr})$ & 8.5 & 5.5 & 9.75 & 0.25 \\
\hline & $V_{\text {daily }}(L /$ day $)$ & 2717 & 2144 & 12187 & 675 \\
\hline Child (10 yrs) & $V_{T}(m L)$ & 304 & 333 & 583 & 752 \\
\hline \multirow[t]{3}{*}{ Male or Female } & $f\left(m^{-1}\right)$ & 17 & 19 & 32 & 45 \\
\hline & $\mathrm{t}(\mathrm{hr})$ & 10 & 4.67 & 9.33 & 0 \\
\hline & $V_{\text {daily }}(L /$ day $)$ & 3101 & 1772 & 10447 & 0 \\
\hline
\end{tabular}

$V_{T}$, tidal volume; $f$, breathing frequency; $t$, time spent engaged in specific activity; $V_{\text {daily, }}$ total volume inspired in $24 \mathrm{hr}$. Data are from ICRP [12] Tables B15 and B16A-B for breathing and activity patterns, respectively. beyond the larynx," whereas the ACGIH thoracic convention for sampling (Figure 1) clearly and intentionally overestimates the fraction of large particles penetrating into the thoracic region to afford extra protection of occupationally exposed individuals. The purpose of this paper is to provide realistic estimates of thoracic and respirable particle fractions for adults and children that may be used in the design of experimental studies and interpretation of health effects evidence.

The ICRP human respiratory tract model [12] was used to estimate particle penetration through the extrathoracic (ET) airways. The ICRP predictive equations for ET deposition are based on experimental measurements in humans. Although also based on human data, the ICRP model was not used to estimate penetration through the tracheobronchial (TB) airways due to its reliance on measurements of particle clearance from the TB airways and the ability to target particle deposition into the ciliated airways. That is, much of the available regional deposition data for the TB and alveolar regions have been obtained from experiments with radioactively labeled, poorly soluble particles or by use of aerosol bolus techniques (see Sections D.9.2 and E.5.3 of Ref [12]). Aerosol bolus (40 ml volume of $3.5 \mu \mathrm{m}$ particles) inhaled to a very shallow lung volume $(70 \mathrm{ml}, \sim 75 \%$ of phase I inert gas washout) by healthy adults $(10 \mathrm{M}, 6 \mathrm{~F}$; 20-43 yrs of age) show preferential left lung deposition and $23 \%$ retention at $48 \mathrm{hrs}$ [13]. This suggests slow TB airway clearance and/or some penetration into the alveolar region. Given the above, coupled with uncertainty related to slow TB clearance [e.g., 14,15], we utilized the publicly available multiple path particle dosimetry (MPPD; ver 2.1, (C) 2009) model to estimate penetration through the TB airways.

\section{Methods}

Once particles have entered the respiratory tract via the nose or mouth, the primary factors affecting particle penetration into the lower respiratory tract (i.e., beyond the larynx) are airways size and structure, breathing pattern (flow and volume), route of breathing (nose vs. mouth), and inhaled particle size. With regard to particle size, we have considered particles whose deposition is governed by their inertial properties, i.e., $\geq 0.5 \mu \mathrm{m}$. Breathing patterns vary mainly by sex, age, and activity. Table 1 provides the breathing patterns, subject groups, and activity patterns from the ICRP [12] model that were used in our assessment.

Based on our comparison of the ICRP model [12] to more recent data provided by Brochu et al. [16], the daily ventilation rates and activity patterns provided in Table 1 overestimate typical daily ventilation rates. Table 2 provides daily ventilation rates $\left(5^{\text {th }}, 50^{\text {th }}\right.$, and $95^{\text {th }}$ percentiles) reported by Brochu et al. [16]. The daily ventilation rates from the ICRP [12] model's recommended time budget roughly correspond to the highly active $95^{\text {th }}$ percentile (see Table 1 vs. Table 2). To assess the effect of daily 
Table 2 Daily ventilation rates $\left(\mathrm{V}_{\text {daily }}\right)_{.}{ }^{a}$

\begin{tabular}{cccc}
\hline & \multicolumn{3}{c}{$\mathbf{V}_{\text {daily }}$ ( $\mathbf{m}^{\mathbf{3}} /$ day) } \\
\cline { 2 - 4 } & $\begin{array}{c}\text { Very sedentary } \\
\mathbf{5}^{\text {th }} \text { percentile }\end{array}$ & $\begin{array}{c}\text { Median } \\
\mathbf{5 0}^{\text {th }} \text { percentile }\end{array}$ & $\begin{array}{c}\text { Highly active } \\
\mathbf{9 5}^{\text {th }} \text { percentile }\end{array}$ \\
\hline Male $^{\mathrm{b}}$ & 12.86 & 17.48 & 22.11 \\
Female $^{\mathrm{b}}$ & 9.91 & 13.67 & 17.42 \\
Children $^{c}$ & 7.20 & 10.22 & 13.24 \\
\hline a & Dan &
\end{tabular}

${ }^{\mathrm{a}}$ Data are from Table 2 of Brochu et al. [16]; ${ }^{\mathrm{b}}$ values for age range of 23 to $<30$ years; ${ }^{c}$ average of male and female values for age range of 7 to $<11$ years.

activity/ventilation rates on particle penetration into the respiratory tract, we reduced the estimated time (given in Table 1) that individuals spent engaged in light exercise and correspondingly increased their time sitting to match the daily ventilation rates in Table 2 . To match the very sedentary $5^{\text {th }}$ percentile of daily activity, it was necessary also to eliminate time spent by the adult female engaged in heavy exercise and to attribute all of the child's activity to sleeping. Even when considering $100 \%$ of the child's activity equivalent to sleeping, the ICRP [12] breathing pattern slightly overestimated (by $3 \% ; 7.4$ vs. $7.2 \mathrm{~m}^{3} /$ day) the $5^{\text {th }}$ percentile daily ventilation rates of Brochu et al. [16].

Route of breathing varies with inspiratory flows and generally shifts from nasal to oronasal breathing at higher flows. The ICRP [12] model characterizes breathing habit based on Niinimaa et al. [17], who examined the route of breathing as a function of activity in healthy adults (14 males, 16 females). Eighty-seven percent of the subjects breathed through the nose at rest and switched to oronasal breathing with exercise. These subjects were referred to as "normal augmenters." Thirteen percent breathed oronasally even at rest and were referred to as "mouth-breathers." For both of these breathing habits (i.e., normal augmenters and mouth-breathers, we estimated the fraction of a breath passing through the oral and nasal pathways from regression equations for oral breathing in Figure 1 of the Niinimaa et al. study [17]. The ICRP [12] model utilizes this same general approach, but for each breathing habit and activity (i.e., sleeping, sitting, etc.), the same fraction of oral breathing was assumed applicable to all ages and both sexes.

In considering breathing habit, we differed from the ICRP, in that we assumed the fraction of oral breathing to differ between adult males and females as a function of their minute ventilation rather than their activity level. However, children tend to have a greater fraction of oral breathing than adults at rest and during exercise $[18,19]$. Therefore, consistent with the ICRP, we assumed the fraction of the breath inhaled through the mouth $\left(\mathrm{F}_{\mathrm{m}}\right)$ in the child engaged in some specific level of activity was equal to that of the adult male engaged in the same level of activity despite the dramatically lower ventilation rates of the child. We also considered recent breathing habit data not available for inclusion in the ICRP model [12]. Bennett et al.
$[19,20]$ show a more gradual increase in oronasal breathing than did Niinimaa et al. [12]. In addition to the normal augmenter and mouth-breather breathing habits based on the Niinimaa et al. [17] study, we also considered the more gradual onset of oronasal breathing observed in adults and children by the Bennett et al. $[19,20]$ studies, herein termed as "gradual augmenters."

The gradual augmenter breathing habit for children was estimated by linear regression of the observed minute ventilation and $\mathrm{F}_{\mathrm{m}}$ at rest and at $40 \%$ maximum physical work capacity from data in Table two and Figure two of Bennett et al. [19] for 12 children (9 M, 3 F; 6-10 yrs of age). The gradual augmenter breathing habit for adult males and females was estimated by linear regression of the observed minute ventilation and $\mathrm{F}_{\mathrm{m}}$ at rest and at $60 \%$ maximum physical work capacity from data in Table two and Figure three of Bennett et al. [20] for 22 adults (11 M, 11 $\mathrm{F}$; mean age, $22 \mathrm{yrs})$. In the adult females, the fitted $\mathrm{F}_{\mathrm{m}}$ was zero for the activity of sitting and so was also set to zero for the activity of sleep. Table 3 provides the $F_{m}$ for all breathing habits (normal augmenters, mouth-breathers, and gradual augmenters) used in our simulations. In a study of 37 subjects from 7-72 years of age, James et al. [21] reported that 2 subjects (5.4\%) breathed orally only. With this finding in mind, we have also considered purely oral breathing in our estimates of particle penetration into regions of the lower respiratory tract.

For air passing through the mouth, deposition of large particles by impaction occurs mainly at the larynx. From Eq D.30 of ICRP [12], laryngeal deposition efficiency, $\eta(E T)_{\text {larynx }}$, is given by:

$$
\eta(E T)_{\text {larynx }}=1-\left\{1.1 \times 10^{-4}\left[d_{a}^{2}\left(Q_{\text {total }} S F^{3}\right)^{0.6}\left(V t S F_{t}^{3}\right)^{-0.2}\right]^{1.4}+1\right\}^{-1}
$$

where: $d_{a}$ is aerodynamic diameter $(\mu \mathrm{m})$; $Q_{\text {total }}$ is total inspiratory flow rate $(\mathrm{mL} / \mathrm{s}) ; \mathrm{V}_{\mathrm{T}}$ is tidal volume $(\mathrm{mL})$; and $\mathrm{SF}_{\mathrm{t}}$ is a scaling factor of 1.0 for adult males, 1.08 for adult females, and 1.26 for ten year-old children from Table fifteen of ICRP [12].

For nasal breathing, ET deposition efficiency due to impaction was calculated from Eq. D.32 and D.33 of ICRP [12]. The ET deposition efficiencies for the anterior, $\eta\left(E_{1}\right)_{\text {nose }}$, and posterior, $\eta\left(E_{2}\right)_{\text {nose }}$, nasal regions are given by:

$$
\begin{aligned}
& \eta\left(E T_{1}\right)_{\text {nose }}=0.5\left\{1-\left[3 \times 10^{-4}\left(d_{a}^{2} Q_{\text {nose }} S F_{t}^{3}\right)+1\right]^{-1}\right\} \\
& \eta\left(E T_{2}\right)_{\text {nose }}=1-\left[5.5 \times 10^{-5}\left(d_{a}^{2} Q_{\text {nose }} S F_{t}^{3}\right)^{1.17}+1\right]^{-1}
\end{aligned}
$$

where: $\mathrm{Q}_{\text {nose }}$ is the inspiratory flow $(\mathrm{mL} / \mathrm{s})$ through the nose. The use of $\mathrm{SF}_{\mathrm{t}}$ in Equations 2 and 3 presumes that 
nasal deposition efficiency increases with decreasing body size and increasing nasal resistance. Two studies $[19,22]$ suggest that the nasal deposition in children is less than that of adults. These two studies, not considered in the ICRP model [12], suggest that it may be inappropriate to apply a scaling factor for nasal deposition of children. Accordingly, we estimated the nasal deposition efficiency of the $10 \mathrm{yr}$ old child for a SF ${ }_{t}$ of both 1.0 (child-A) and 1.26 (child-B). Additionally, we estimated the upper and lower $95 \%$ confidence bounds for inter-individual variability attributable to differences in deposition efficiency within the ET region predicted by Equations 1-3 as specified in paragraphs D44 and D68 of ICRP [12].

The deposition efficiencies along the ET pathways (i.e., nasal and oral) were assumed to be independent. As such, total ET deposition was taken to be the sum of deposition between the pathways weighted by the flow partitioning (see Paragraph 161 of ICRP [12]). The thoracic fraction, defined as particle penetration past the larynx, $\mathrm{P}(\mathrm{ET})$, is given by:

$$
\begin{aligned}
P(E T)= & 1-F_{m} \eta(E T)_{\text {larynx }}-\left(1-F_{m}\right) \\
& \times\left[\eta\left(E T_{1}\right)_{\text {nose }}+\left(1-\eta\left(E T_{1}\right)_{\text {nose }}\right) \eta\left(E T_{2}\right)_{\text {nose }}\right]
\end{aligned}
$$

We estimated inspiratory deposition efficiency in the TB region, $\eta_{\mathrm{TB}}$, of particles $(0.5-20 \mu \mathrm{m} ; 0.1 \mu \mathrm{m}$ increments) using the publicly available multiple path particle dosimetry (MPPD; ver 2.1, () 2009) model..$^{\mathrm{d}}$ The model considers deposition by the mechanisms of impaction, sedimentation, and diffusion. The approach and formula used to calculate particle losses in the MPPD model are described by Anjilvel and Asgharian [23]. Physiological input parameters (namely, tidal volume $\left[\mathrm{V}_{\mathrm{T}}\right]$, breathing frequency $[\mathrm{f}]$, functional residual capacity $[\mathrm{FRC}]$, and upper respiratory tract volume [URT]), necessary for MPPD simulations are provided in Tables 1 and 4. FRC and URT for each group are from Table fifteen of ICRP [12]. The Yeh and Schum [24] typical path whole lung model was utilized and scaled for FRC and $V_{T}$. The effects of these physiologic parameters on deposition in humans free of respiratory disease are described by de Winter-Sorkina and Cassee [25].

The respiratory fraction, defined as particle penetration through the ciliated airways of the TB region, $\mathrm{P}$ (TB), is given by:

$$
P(T B)=\frac{\int_{0}^{T_{\text {inh }}} C_{1} d t}{\int_{0}^{T_{\text {inh }}} C_{0} d t} \cong P(E T)\left(1-\eta_{T B}\right)
$$

where: $C_{0}$ and $C_{1}$ are particle concentration passing the larynx and terminal bronchioles, respectively; and $\mathrm{T}_{\mathrm{inh}}$ is the time of inhalation. Since conducting airway particle concentration is nearly constant during inhalation, respiratory fraction can be expressed in terms of TB deposition efficiency as given above. An Additional file 1: Appendix to this paper provides estimates of $\mathrm{P}(\mathrm{TB})$ based on the ICRP [12] model rather than the MPPD model.

After calculating $\mathrm{P}(\mathrm{ET})$ and $\mathrm{P}(\mathrm{TB})$ for all activities and individual groups, daily average estimates of $\mathrm{P}(\mathrm{ET})_{\text {avg }}$ and $\mathrm{P}(\mathrm{TB})$ avg weighted by daily ventilation (see Tables 1 and 2) were calculated as a function of particle size. Ventilation-weighted averages of $\mathrm{P}(\mathrm{ET})_{\text {avg }}$ for each particle size were calculated as:

$$
P(E T)_{\text {avg }}=\sum_{i=1}^{n}\left[P(E T)_{i} V_{\text {daily }-i}\right] / \sum_{i=1}^{n} V_{\text {daily }-i}
$$

where: $\mathrm{P}(\mathrm{ET})_{\mathrm{i}}$ is the $\mathrm{ET}$ fraction for activity, $i$; $\mathrm{V}_{\text {daily-i }}$ is the daily volume inhaled while engaged in activity, $i$; and $n$ is the number of activities. Ventilation-weighted averages of $\mathrm{P}(\mathrm{TB})_{\text {avg }}$ were computed similarly to those of $\mathrm{P}(\mathrm{ET})_{\text {avg. }}$.

Finally, thoracic and respiratory particle fractions were also calculated after applying the ICRP [12] inhalability criterion assuming no ambient wind, $1-0.5\left[1-\left(0.00076 \mathrm{~d}_{\mathrm{a}}^{2.8}+1\right)^{-1}\right]$. The ICRP [12] criterion was utilized as it better represents the inhalation of particles $<10 \mu \mathrm{m}$ than the ACGIH and CEN $[2,3]$ criterion.

\section{Results}

We estimated particle penetration fractions into the thorax

\begin{tabular}{|c|c|c|c|c|c|}
\hline & & Sleeping & Sitting & $\begin{array}{r}\text { Light } \\
\text { Exercise }\end{array}$ & $\begin{array}{r}\text { Heavy } \\
\text { Exercise }\end{array}$ \\
\hline \multirow[t]{3}{*}{$\begin{array}{l}\text { Adult } \\
\text { Male }\end{array}$} & $\begin{array}{r}\text { Normal } \\
\text { Augmenter }\end{array}$ & $0,1.00^{d}$ & $0,1.00$ & $0,1.00$ & $0.52,0.48$ \\
\hline & $\begin{array}{l}\text { Mouth- } \\
\text { breather }\end{array}$ & $0.29,0.71$ & $0.36,0.64$ & $0.59,0.41$ & $0.66,0.34$ \\
\hline & $\begin{array}{r}\text { Gradual } \\
\text { Augmenter }\end{array}$ & $0.12,0.88$ & $0.13,0.87$ & $0.29, .071$ & $0.54,0.46$ \\
\hline \multirow[t]{3}{*}{$\begin{array}{l}\text { Adult } \\
\text { Female }\end{array}$} & $\begin{array}{l}\text { Normal } \\
\text { Augmenter }^{\mathrm{a}}\end{array}$ & $0,1.00$ & $0,1.00$ & $0,1.00$ & $0.50,0.50$ \\
\hline & $\begin{array}{l}\text { Mouth- } \\
\text { breather }{ }^{a}\end{array}$ & $0.12,0.88$ & $0.23,0.77$ & $0.57,0.43$ & $0.65,0.35$ \\
\hline & $\begin{array}{r}\text { Gradual } \\
\text { Augmenter }\end{array}$ & $0,1.00$ & $0,1.00$ & $0.22,0.78$ & $0.59,0.41$ \\
\hline \multirow[t]{3}{*}{ Child } & $\begin{array}{l}\text { Normal } \\
\text { Augmenter }^{\mathrm{a}}\end{array}$ & $0,1.00$ & $0,1.00$ & $0,1.00$ & $0.51,0.49$ \\
\hline & $\begin{array}{l}\text { Mouth- } \\
\text { breather }\end{array}$ & $0.29,0.71$ & $0.36,0.64$ & $0.59,0.41$ & $0.66,0.34$ \\
\hline & $\begin{array}{r}\text { Gradual } \\
\text { Augmenter }^{c}\end{array}$ & $0.29,0.71$ & $0.31,0.69$ & $0.51,0.49$ & $0.77,0.23$ \\
\hline
\end{tabular}
and respiratory region of an adult male, adult female, and a

Table 3 Partitioning of breaths through the mouth and nose

arom regression equations for oral breathing in Figure 1 of Niinimaa et al. [17]; ${ }^{b}$ Data based on Table 2 and Figure 3 of Bennett et al. [20] for 22 individuals ( $11 \mathrm{M}, 11 \mathrm{~F}$; mean age, $22 \mathrm{yrs}){ }^{\mathrm{C}}{ }^{\mathrm{C}}$ Data based on Table 2 and Figure 2 of Bennett et al. [19] for 12 children (9 M, 3 F; 6-10 yrs of age); ${ }^{d}$ fraction inhaled through mouth, fraction inhaled through nose. 
10 yr old child. In the results described below, data do not consider particle inhalability unless specifically stated. Inhalability was not considered since, as the results will show, it has a minimal affect on $50 \%$ cut-points for particle penetration into the lower airways for all breathing habits except the less probable condition of oral breathing.

\section{Route of breathing}

Of the factors we considered, route of breathing (or breathing habit) had the greatest effect on estimates of $\mathrm{P}(\mathrm{ET})$ and $\mathrm{P}(\mathrm{TB})$. Figure 2 and 3 illustrate $\mathrm{P}(\mathrm{ET})$ and $\mathrm{P}(\mathrm{TB})$ for an adult male engaged in light exercise as a function of $\mathrm{F}_{\mathrm{m}}$. In Figure 2, fifty percent $\mathrm{P}(\mathrm{ET})$ occurs at the $\mathrm{d}_{\mathrm{a}}$ of $1.8,2.7$, $4.4,6.1$, and $7.0 \mu \mathrm{m}$ for the $F_{m}$ of $0.00,0.25,0.50,0.75$, and 1.00 , respectively. Note that the curve in Figure 2 for $F_{m}=1$ is for comparable conditions to those for which ACGIH [4] thoracic fraction was based, i.e. an orally breathing adult male engaged in light exercise. In Figure 3, fifty percent $\mathrm{P}$ (TB) occurs at the $d_{a}$ of $1.7,2.5,3.8,5.1$, and $5.7 \mu \mathrm{m}$ for the $\mathrm{F}_{\mathrm{m}}$ of $0.00,0.25,0.50,0.75$, and 1.00 , respectively. As ventilation is shifted to the lower removal efficiency oral passages, there is an ever greater separation between the $\mathrm{P}$ (ET) and $\mathrm{P}(\mathrm{TB})$ curves. By contrast, for purely nasal breathing $\left(\mathrm{F}_{\mathrm{m}}=0\right.$, the case for normal augmenters during light exercise), due to the vast removal of particles in the nasal airways, there is nearly no difference between the $\mathrm{P}(\mathrm{ET})$ and $\mathrm{P}(\mathrm{TB})$ curves in Figures 2 and 3, respectively.

Table 5 provides the $50 \%$ cut-points for particle penetration into the thorax and respiratory region for all the breathing habits we evaluated. As may be expected based on $F_{m}$ (see Table 3), the predicted particle penetration for the gradual augmenter breathing habit is enveloped between that of the normal augmenter and mouth-breathers. Additionally, consistent with Figures 2 and 3, Table 5 shows that the largest $50 \%$ cut-points are observed during the case of oral breathing. Table 6 provides data on the penetration of $10 \mu \mathrm{m}$ particles into the lower respiratory tract which is generally less than $20 \%$, except for the case of oral breathing where penetration into the thorax can approach $40 \%$.

\section{Age and sex}

Daily weighted penetrations curves for $\mathrm{P}(\mathrm{ET})_{\mathrm{avg}}$ and $\mathrm{P}(\mathrm{TB})_{\text {avg }}$ are illustrated in Figures 4 and 5, respectively. For normal augmenters and oral breathing, 50\% cutpoints for $\mathrm{P}(\mathrm{ET})_{\text {avg }}$ and $\mathrm{P}(\mathrm{TB})_{\text {avg }}$ were generally similar

Table 4 Functional residual volume (FRC) and upper respiratory tract volumes (URT)

\begin{tabular}{lll}
\hline & FRC $(\mathbf{m L})$ & URT $(\mathbf{m L})$ \\
\hline Adult Male & 3300 & 50 \\
Adult Female & 2680 & 40 \\
Child (10 yrs) & 1484 & 25 \\
\hline
\end{tabular}

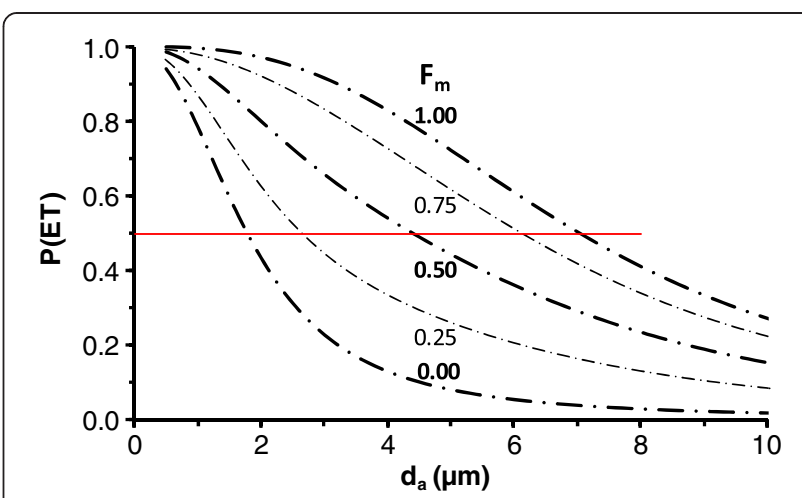

Figure 2 Thoracic fraction, i.e., particle penetration through the extrathoracic region, $\mathrm{P}(\mathrm{ET})$, as a function of breathing route. Penetration data are with respect to particle diameter as a function of the fraction of air inhaled through the mouth $\left(F_{m}\right)$ in an adult male engaged in light exercise relative to particles entering the respiratory tract. Curves are for the $F_{m}$ of $0.00,0.25,0.50,0.75$, and 1.00 as indicated on the figure. Horizontal red line highlights $50 \%$ penetration.

between adult males and females, but shifted to slightly $(<0.2 \mu \mathrm{m})$ smaller particle sizes in the females (see Table 5). There was a larger $(<0.8 \mu \mathrm{m})$ difference in $50 \%$ cut-points between males and females for the mouth-breather and gradual augmenter breathing habits which is attributable to greater nasal inhalation by females than males.

The data for child-A are more consistent, than child-B, with experimental data $[19,22]$ showing a lower nasal particle removal efficiency in children than adults. For all breathing habits except oral breathing in Table 5, child-A shows larger $50 \%$ cut-points than adults. Additionally, in Table 6 , the penetration of $10 \mu \mathrm{m}$ particles into the thoracic and respiratory regions of child-A is generally greater than or equal to that of adults for all breathing habits other

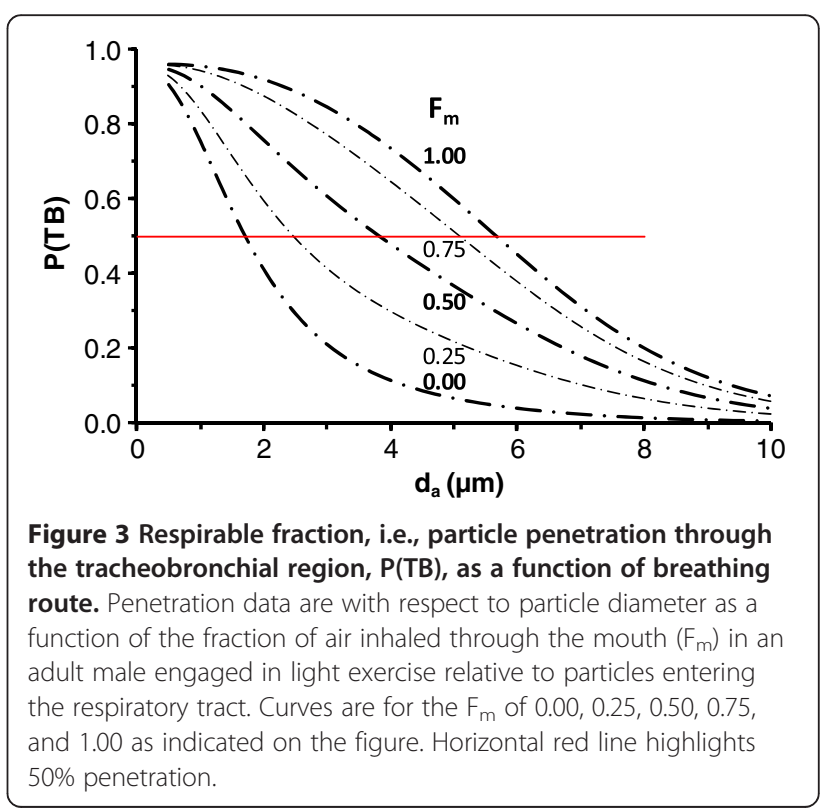


Table 5 Particle penetration (50\% cut-point) through respiratory tract regions relative to particles entering the respiratory tract

\begin{tabular}{|c|c|c|c|c|c|c|c|c|}
\hline \multirow[t]{3}{*}{$\mathrm{V}_{\text {daily }}(\%$-tile) } & \multirow{2}{*}{\multicolumn{2}{|c|}{$\begin{array}{c}\text { Normal } \\
\text { Augmenter }\end{array}$}} & \multicolumn{6}{|c|}{ Gradual } \\
\hline & & & \multicolumn{2}{|c|}{ Mouth-breather } & \multicolumn{2}{|c|}{ Augmenter } & \multicolumn{2}{|c|}{ Oral only } \\
\hline & $\mathrm{P}(\mathrm{ET})_{\mathrm{avg}}$ & $\mathrm{P}(\mathrm{TB})_{\mathrm{avg}}$ & $\mathrm{P}(\mathrm{ET})_{\mathrm{avg}}$ & $\mathrm{P}(\mathrm{TB})_{\mathrm{avg}}$ & $\mathrm{P}(\mathrm{ET})_{\mathrm{avg}}$ & $\mathrm{P}(\mathrm{TB})_{\mathrm{avg}}$ & $\mathrm{P}(\mathrm{ET})_{\mathrm{avg}}$ & $\mathrm{P}(\mathrm{TB})_{\text {avg }}$ \\
\hline \multicolumn{9}{|l|}{ Male } \\
\hline $5 \%$ & $2.94^{a}$ & 2.74 & 5.15 & 4.32 & 3.60 & 3.25 & 9.00 & 6.67 \\
\hline $95 \% \mathrm{Cl}$ & $(1.72-5.03)$ & $(1.65-4.34)$ & $(3.12-8.48)$ & $(2.84-6.10)$ & $(2.11-6.11)$ & $(2.00-4.98)$ & $(5.86-13.8)$ & $(5.00-8.14)$ \\
\hline $50 \%$ & 2.46 & 2.30 & 5.09 & 4.30 & 3.37 & 3.05 & 8.09 & 6.11 \\
\hline $95 \% \mathrm{Cl}$ & $(1.44-4.20)$ & $(1.38-3.71)$ & $(3.14-8.26)$ & $(2.86-5.88)$ & $(1.99-5.67)$ & $(1.88-4.65)$ & $(5.26-12.4)$ & $(4.58-7.34)$ \\
\hline $95 \%$ & 2.14 & 2.03 & 5.08 & 4.31 & 3.19 & 2.90 & 7.61 & 5.89 \\
\hline $95 \% \mathrm{Cl}$ & $(1.25-3.66)$ & $(1.20-3.32)$ & $(3.16-8.16)$ & $(2.89-5.83)$ & $(1.90-5.33)$ & $(1.79-4.44)$ & $(4.95-11.7)$ & $(4.38-7.07)$ \\
\hline \multicolumn{9}{|l|}{ Female } \\
\hline $5 \%$ & 2.92 & 2.71 & 4.32 & 3.78 & 3.10 & 2.86 & 8.78 & 6.50 \\
\hline $95 \% \mathrm{Cl}$ & $(1.71-5.01)$ & $(1.63-4.28)$ & $(2.57-7.22)$ & $(2.40-5.52)$ & $(1.81-5.30)$ & $(1.73-4.48)$ & $(5.71-13.5)$ & $(4.88-7.91)$ \\
\hline $50 \%$ & 2.42 & 2.27 & 4.46 & 3.87 & 2.91 & 2.68 & 7.88 & 5.96 \\
\hline $95 \% \mathrm{Cl}$ & $(1.41-4.13)$ & $(1.36-3.64)$ & $(2.72-7.32)$ & $(2.51-5.45)$ & $(1.71-4.94)$ & $(1.63-4.19)$ & $(5.13-12.1)$ & $(4.47-7.17)$ \\
\hline $95 \%$ & 2.10 & 1.99 & 4.58 & 3.96 & 2.74 & 2.54 & 7.44 & 5.77 \\
\hline $95 \% \mathrm{Cl}$ & $(1.23-3.60)$ & $(1.18-3.26)$ & $(2.82-7.42)$ & $(2.60-5.49)$ & $(1.61-4.64)$ & $(1.53-4.00)$ & $(4.84-11.4)$ & $(4.29-6.94)$ \\
\hline \multicolumn{9}{|l|}{ Child-B $^{b}$} \\
\hline $5 \%$ & 2.77 & 2.61 & 4.31 & 3.78 & 4.30 & 3.78 & 8.34 & 6.46 \\
\hline $95 \% \mathrm{Cl}$ & $(1.62-4.75)$ & $(1.56-4.18)$ & $(2.58-7.19)$ & $(2.40-5.57)$ & $(2.57-7.17)$ & $(2.40-5.56)$ & $(5.42-12.8)$ & $(4.74-8.04)$ \\
\hline $50 \%$ & 2.25 & 2.13 & 4.37 & 3.81 & 4.07 & 3.59 & 7.50 & 5.81 \\
\hline $95 \% \mathrm{Cl}$ & $(1.31-3.85)$ & $(1.27-3.48)$ & $(2.67-7.15)$ & $(2.47-5.35)$ & $(2.46-6.71)$ & $(2.29-5.15)$ & $(4.88-11.5)$ & $(4.32-7.08)$ \\
\hline $95 \%$ & 1.89 & 1.81 & 4.34 & 3.76 & 3.98 & 3.49 & 6.91 & 5.33 \\
\hline $95 \% \mathrm{Cl}$ & $(1.11-3.24)$ & $(1.07-2.98)$ & $(2.69-7.03)$ & $(2.48-5.11)$ & $(2.45-6.47)$ & $(2.27-4.88)$ & $(4.49-10.6)$ & $(4.01-6.36)$ \\
\hline \multicolumn{9}{|l|}{ Child-A ${ }^{c}$} \\
\hline $5 \%$ & 3.92 & 3.56 & 5.60 & 4.72 & 5.59 & 4.72 & 8.34 & 6.46 \\
\hline $95 \% \mathrm{Cl}$ & $(2.29-6.72)$ & $(2.18-5.44)$ & $(3.38-9.28)$ & $(3.09-6.63)$ & $(3.37-9.27)$ & $(3.09-6.62)$ & $(5.42-12.8)$ & $(4.74-8.04)$ \\
\hline $50 \%$ & 3.18 & 2.94 & 5.37 & 4.53 & 5.12 & 4.36 & 7.50 & 5.81 \\
\hline $95 \% \mathrm{Cl}$ & $(1.86-5.45)$ & $(1.77-4.58)$ & $(3.29-8.77)$ & $(3.03-6.10)$ & $(3.11-8.40)$ & $(2.88-5.95)$ & $(4.88-11.5)$ & $(4.32-7.08)$ \\
\hline $95 \%$ & 2.68 & 2.50 & 5.16 & 4.34 & 4.85 & 4.14 & 6.91 & 5.33 \\
\hline $95 \% \mathrm{Cl}$ & $(1.56-4.58)$ & $(1.50-3.97)$ & (3.19-8.34) & $(2.94-5.66)$ & $(2.98-7.90)$ & $(2.76-5.51)$ & $(4.49-10.6)$ & $(4.01-6.36)$ \\
\hline
\end{tabular}

$\mathrm{P}(\mathrm{ET})_{\text {avg, }}$ extrathoracic particle penetration which is the thoracic particle fraction averaged across all activity levels weighted by daily ventilation; $\mathrm{P}(\mathrm{TB})_{\text {avg }}$ tracheobronchial particle penetration which is the respirable particle fraction averaged across all activity levels weighted by daily ventilation; $95 \% \mathrm{Cl}$, ninety-five percent confidence intervals for inter-individual variability attributable to differences in particle penetration through the extrathoracic region; ${ }^{a}$ Aerodynamic particle diameter in $\mu \mathrm{m} ;{ }^{\mathrm{b}}$ Scaling factor in Equations 2 and 3 equal to $1.26 ;{ }^{\mathrm{C}}$ Scaling factor in Equations 2 and 3 equal to 1.0.

than oral. For oral breathing, the penetration of $10 \mu \mathrm{m}$ particles is lower in child-A than adults.

\section{Activity level}

Impaction in the nasal airways, larynx, and large bronchi increases in conjunction with activity and increasing inspiratory flows across the range of $\mathrm{d}_{\mathrm{a}}$. Therefore, decreasing $50 \%$ cut-points for both $\mathrm{P}(\mathrm{ET})_{\mathrm{avg}}$ and $\mathrm{P}(\mathrm{TB})_{\text {avg }}$ are observed with increasing activity. In general, the penetration of $10 \mu \mathrm{m}$ particles into the thoracic and respiratory regions also showed a small reduction with increasing daily activity level (see Table 6). However, the small reductions in particle penetration pale in comparison to the large increases in ventilation and intake of particles that occur with increasing activity level.

\section{Inhalability adjustment}

The thoracic and respirable fraction data in Table 5 were relative to particles entering the respiratory tract. For comparison, Table 7 provides $d_{a}$ associated with $50 \%$ penetration into the thorax and respiration regions after applying inhalability criterion. Adjusting for inhalability shifts penetration curves to smaller particle sizes, and this effect is most evident where there is a low activity level and a 
Table 6 Penetration of $10 \mu \mathrm{m}\left(d_{a}\right)$ through respiratory tract regions relative to particles entering the respiratory tract

\begin{tabular}{|c|c|c|c|c|c|c|c|c|}
\hline \multirow{3}{*}{$\begin{array}{r}\mathrm{V}_{\text {daily }} \\
\text { (\%-tile) }\end{array}$} & \multirow{2}{*}{\multicolumn{2}{|c|}{$\begin{array}{c}\text { Normal } \\
\text { Augmenter }^{\mathrm{a}}\end{array}$}} & \multicolumn{6}{|c|}{ Gradual } \\
\hline & & & \multicolumn{2}{|c|}{ Mouth-breather ${ }^{a}$} & \multicolumn{2}{|c|}{ Augmenter $^{a}$} & \multicolumn{2}{|c|}{ Oral only ${ }^{a}$} \\
\hline & $\mathrm{P}(\mathrm{ET})_{\mathrm{avg}}$ & $\mathrm{P}(\mathrm{TB})_{\mathrm{avg}}$ & $\mathrm{P}(\mathrm{ET})_{\mathrm{avg}}$ & $\mathrm{P}(\mathrm{TB})_{\mathrm{avg}}$ & $\mathrm{P}(\mathrm{ET})_{\mathrm{avg}}$ & $\mathrm{P}(\mathrm{TB})_{\mathrm{avg}}$ & $\mathrm{P}(\mathrm{ET})_{\mathrm{avg}}$ & $\mathrm{P}(\mathrm{TB})_{\text {avg }}$ \\
\hline \multicolumn{9}{|l|}{ Male } \\
\hline $5 \%$ & $0.05^{\mathrm{b}}$ & 0.03 & 0.21 & 0.10 & 0.11 & 0.05 & 0.43 & 0.21 \\
\hline $50 \%$ & 0.04 & 0.02 & 0.19 & 0.08 & 0.11 & 0.04 & 0.36 & 0.15 \\
\hline $95 \%$ & 0.03 & 0.01 & 0.19 & 0.06 & 0.10 & 0.03 & 0.32 & 0.12 \\
\hline \multicolumn{9}{|l|}{ Female } \\
\hline $5 \%$ & 0.06 & 0.03 & 0.15 & 0.07 & 0.06 & 0.03 & 0.41 & 0.20 \\
\hline $50 \%$ & 0.04 & 0.02 & 0.15 & 0.06 & 0.07 & 0.02 & 0.35 & 0.14 \\
\hline $95 \%$ & 0.03 & 0.01 & 0.16 & 0.05 & 0.07 & 0.02 & 0.31 & 0.11 \\
\hline \multicolumn{9}{|l|}{ Child-B $^{c}$} \\
\hline $5 \%$ & 0.05 & 0.02 & 0.16 & 0.08 & 0.16 & 0.08 & 0.38 & 0.18 \\
\hline $50 \%$ & 0.03 & 0.01 & 0.15 & 0.06 & 0.14 & 0.06 & 0.31 & 0.13 \\
\hline $95 \%$ & 0.02 & 0.01 & 0.14 & 0.04 & 0.13 & 0.04 & 0.27 & 0.09 \\
\hline \multicolumn{9}{|l|}{ Child-A $^{d}$} \\
\hline $5 \%$ & 0.10 & 0.05 & 0.21 & 0.10 & 0.21 & 0.10 & 0.38 & 0.18 \\
\hline $50 \%$ & 0.07 & 0.04 & 0.19 & 0.09 & 0.18 & 0.07 & 0.31 & 0.13 \\
\hline $95 \%$ & 0.05 & 0.02 & 0.17 & 0.05 & 0.16 & 0.05 & 0.27 & 0.09 \\
\hline
\end{tabular}

$\mathrm{P}(\mathrm{ET})$, extrathoracic penetration for $10 \mu \mathrm{m}$ particles; $\mathrm{P}(\mathrm{TB})$, tracheobronchial penetration for $10 \mu \mathrm{m}$ particles; ${ }^{\mathrm{a} D a t a}$ are daily averages, all activity levels weighted by daily ventilation; ${ }^{b}$ Fraction penetration; 'Scaling factor in Equations 2 and 3 equal to 1.26; ${ }^{\mathrm{d}}$ Scaling factor in Equations 2 and 3 equal to 1.0.

substantial contribution of oral breathing. Table 6 provides data on the penetration of $10 \mu \mathrm{m}$ particles into the lower respiratory tract. Those penetration data may be adjusted for inhalability by multiplying by 0.84 , the inhalability of $10 \mu \mathrm{m}$ particles.

\section{Discussion}

We calculated thoracic and respirable particle fractions for an adult male, adult female, and ten year-old child

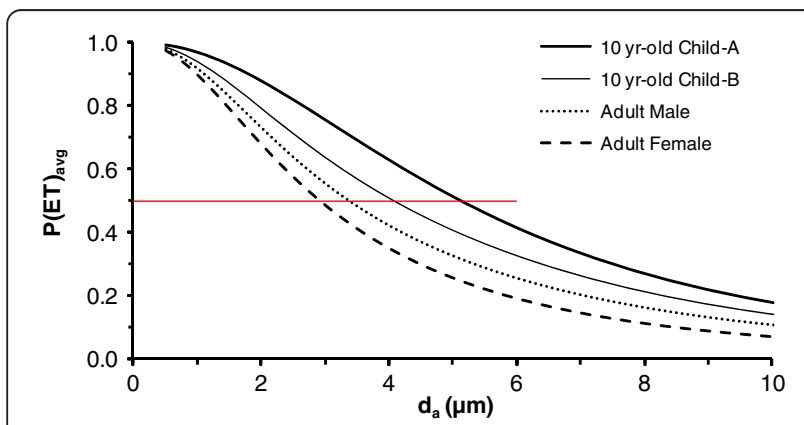

Figure 4 Thoracic fraction, i.e., particle penetration through the extrathoracic region, $\mathrm{P}(\mathrm{ET})_{\text {avg, }}$ in adults and a $10 \mathrm{yr}$-old child. Data are daily averaged values for a median activity level, gradual augmenter breathing habit, and uncorrected for particle inhalability. Child-A and child-B are for a scaling factor of 1.0 and 1.26 in Equations 2 and 3, respectively. Horizontal red line highlights 50\% penetration which occurs at $3.1 \mu \mathrm{m}$ (adult female), $3.4 \mu \mathrm{m}$ (adult male), $4.1 \mu \mathrm{m}$ (child-B), and $5.1 \mu \mathrm{m}$ (child-A). engaged in typical daily activities ranging from sleep to heavy exercise. Our estimates are intended to represent full-day ambient and/or non-ambient exposures while individuals are engaged in a variety of activities. This differs from the ACGIH and CEN criteria which are intended to represent a workplace setting $[2,4]$. Similarly, considering the need to provide protection for sensitive individuals who may breathe by mouth and/or oronasally, the EPA [8] selected the nominal cut-point of $10 \mu \mathrm{m}$ as an

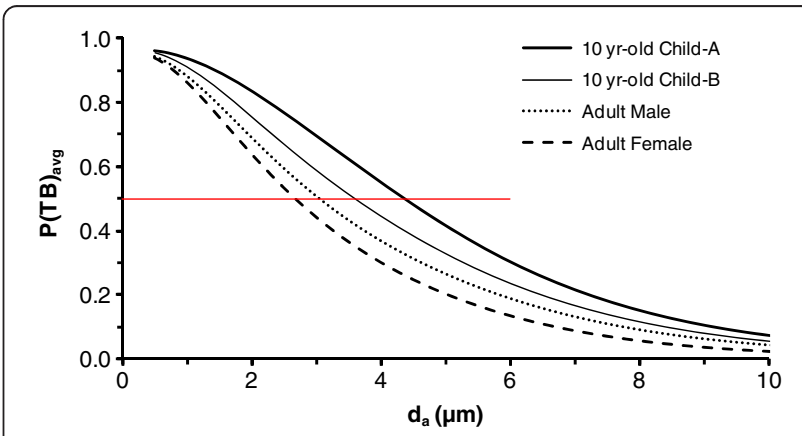

Figure 5 Respirable fraction, i.e., particle penetration through the tracheobronchial region, $\mathrm{P}(\mathrm{TB})_{\mathrm{avg}}$, in adults and a $10 \mathrm{yr}$-old child. Data are daily averaged values for a median activity level, gradual augmenter breathing habit, and uncorrected for particle inhalability. Child-A and child-B are for a scaling factor of 1.0 and 1.26 in Equations 2 and 3, respectively. Horizontal red line highlights 50\% penetration which occurs at $2.7 \mu \mathrm{m}$ (adult female), $3.1 \mu \mathrm{m}$ (adult male), $3.6 \mu \mathrm{m}$ (child-B), and $4.4 \mu \mathrm{m}$ (child-A). 
Table 7 Inhalability adjusted particle penetration (50\% cut-point) through respiratory tract regions

\begin{tabular}{|c|c|c|c|c|c|c|c|c|}
\hline \multirow{3}{*}{$\begin{array}{r}\mathrm{V}_{\text {daily }} \\
\text { (\%-tile) }\end{array}$} & \multirow{2}{*}{\multicolumn{2}{|c|}{$\begin{array}{c}\text { Normal } \\
\text { Augmenter }\end{array}$}} & \multicolumn{6}{|c|}{ Gradual } \\
\hline & & & \multicolumn{2}{|c|}{ Mouth-breather } & \multicolumn{2}{|c|}{ Augmenter } & \multicolumn{2}{|c|}{ Oral only } \\
\hline & $\mathrm{P}(\mathrm{ET})_{\mathrm{avg}}$ & $\mathrm{P}(\mathrm{TB})_{\mathrm{avg}}$ & $\mathrm{P}(\mathrm{ET})_{\text {avg }}$ & $\mathrm{P}(\mathrm{TB})_{\text {avg }}$ & $\mathrm{P}(\mathrm{ET})_{\text {avg }}$ & $\mathrm{P}(\mathrm{TB})_{\mathrm{avg}}$ & $\mathrm{P}(\mathrm{ET})_{\mathrm{avg}}$ & $\mathrm{P}(\mathrm{TB})_{\text {avg }}$ \\
\hline \multicolumn{9}{|l|}{ Male } \\
\hline $5 \%$ & $2.92^{a}$ & 2.72 & 4.97 & 4.24 & 3.55 & 3.22 & 8.24 & 6.38 \\
\hline $95 \% \mathrm{Cl}$ & $(1.71-4.90)$ & $(1.64-4.26)$ & $(3.09-7.66)$ & $(2.81-5.85)$ & $(2.11-5.82)$ & $(2.00-4.85)$ & $(5.66-11.4)$ & $(4.89-7.59)$ \\
\hline $50 \%$ & 2.44 & 2.30 & 4.93 & 4.21 & 3.33 & 3.02 & 7.52 & 5.90 \\
\hline $95 \% \mathrm{Cl}$ & $(1.43-4.12)$ & $(1.37-3.67)$ & $(3.11-7.51)$ & $(2.84-5.67)$ & $(1.99-5.43)$ & $(1.87-4.54)$ & $(5.12-10.5)$ & $(4.50-6.98)$ \\
\hline $95 \%$ & 2.14 & 2.02 & 4.92 & 4.22 & 3.15 & 2.88 & 7.14 & 5.71 \\
\hline $95 \% \mathrm{Cl}$ & $(1.25-3.62)$ & $(1.20-3.29)$ & $(3.13-7.44)$ & $(2.87-5.64)$ & $(1.89-5.15)$ & $(1.78-4.36)$ & $(4.84-10.1)$ & $(4.32-6.77)$ \\
\hline \multicolumn{9}{|l|}{ Female } \\
\hline $5 \%$ & 2.90 & 2.70 & 4.22 & 3.72 & 3.08 & 2.85 & 8.06 & 6.23 \\
\hline $95 \% \mathrm{Cl}$ & $(1.70-4.87)$ & $(1.63-4.20)$ & $(2.56-6.73)$ & $(2.38-5.34)$ & $(1.81-5.13)$ & $(1.73-4.40)$ & $(5.53-11.2)$ & $(4.78-7.41)$ \\
\hline $50 \%$ & 2.41 & 2.26 & 4.36 & 3.81 & 2.89 & 2.67 & 7.35 & 5.77 \\
\hline $95 \% \mathrm{Cl}$ & $(1.41-4.06)$ & $(1.35-3.60)$ & $(2.70-6.80)$ & $(2.50-5.29)$ & $(1.71-4.79)$ & $(1.63-4.12)$ & $(5.00-10.3)$ & $(4.39-6.83)$ \\
\hline $95 \%$ & 2.10 & 1.99 & 4.46 & 3.89 & 2.72 & 2.52 & 7.00 & 5.60 \\
\hline $95 \% \mathrm{Cl}$ & $(1.23-3.55)$ & $(1.18-3.23)$ & $(2.80-6.87)$ & $(2.58-5.33)$ & $(1.61-4.42)$ & $(1.53-3.93)$ & $(4.74-9.91)$ & $(4.22-6.66)$ \\
\hline \multicolumn{9}{|l|}{ Child-B $^{b}$} \\
\hline $5 \%$ & 2.76 & 2.60 & 4.22 & 3.73 & 4.21 & 3.72 & 7.73 & 6.20 \\
\hline $95 \% \mathrm{Cl}$ & $(1.62-4.64)$ & $(1.56-4.11)$ & $(2.56-6.69)$ & $(2.39-5.38)$ & $(2.56-6.68)$ & $(2.39-5.37)$ & $(5.28-10.8)$ & $(4.65-7.52)$ \\
\hline $50 \%$ & 2.24 & 2.13 & 4.27 & 3.75 & 3.99 & 3.54 & 7.05 & 5.63 \\
\hline $95 \% \mathrm{Cl}$ & $(1.31-3.79)$ & $(1.27-3.44)$ & $(2.65-6.66)$ & $(2.46-5.20)$ & $(2.45-6.30)$ & $(2.28-5.01)$ & (4.77-9.98) & $(4.25-6.74)$ \\
\hline $95 \%$ & 1.89 & 1.80 & 4.25 & 3.71 & 3.91 & 3.45 & 6.56 & 5.21 \\
\hline $95 \% \mathrm{Cl}$ & $(1.10-3.21)$ & $(1.07-2.96)$ & $(2.67-6.56)$ & $(2.47-4.99)$ & $(2.42-6.12)$ & $(2.25-4.78)$ & $(4.42-9.37)$ & $(3.96-6.15)$ \\
\hline \multicolumn{9}{|l|}{ Child-A ${ }^{c}$} \\
\hline $5 \%$ & 3.87 & 3.52 & 5.40 & 4.62 & 5.39 & 4.61 & 7.73 & 6.20 \\
\hline $95 \% \mathrm{Cl}$ & $(2.28-6.36)$ & $(2.17-5.27)$ & $(3.34-8.32)$ & $(3.07-6.32)$ & $(3.34-8.31)$ & $(3.06-6.31)$ & $(5.28-10.8)$ & $(4.65-7.52)$ \\
\hline $50 \%$ & 3.15 & 2.92 & 5.20 & 4.44 & 4.96 & 4.28 & 7.05 & 5.63 \\
\hline $95 \% \mathrm{Cl}$ & $(1.85-5.29)$ & $(1.77-4.49)$ & $(3.26-7.96)$ & $(3.00-5.88)$ & $(3.09-7.66)$ & $(2.86-5.75)$ & $(4.77-9.98)$ & $(4.25-6.74)$ \\
\hline $95 \%$ & 2.66 & 2.49 & 5.00 & 4.26 & 4.73 & 4.07 & 6.56 & 5.21 \\
\hline $95 \% \mathrm{Cl}$ & $(1.56-4.47)$ & $(1.50-3.91)$ & $(3.16-7.64)$ & $(2.92-5.51)$ & $(2.96-7.29)$ & $(2.74-5.39)$ & $(4.42-9.37)$ & $(3.96-6.15)$ \\
\hline
\end{tabular}

$\mathrm{P}(\mathrm{ET})_{\text {avg, }}$ extrathoracic particle penetration which is the thoracic particle fraction averaged across all activity levels weighted by daily ventilation; $\mathrm{P}(\mathrm{TB})_{\text {avg }}$ tracheobronchial particle penetration which is the respirable particle fraction averaged across all activity levels weighted by daily ventilation; $95 \% \mathrm{Cl}$, ninety-five percent confidence intervals for inter-individual variability attributable to differences in particle penetration through the extrathoracic region; ${ }^{a}$ Aerodynamic particle diameter in $\mu \mathrm{m} ;{ }^{\mathrm{b}}$ Scaling factor in Equations 2 and 3 equal to $1.26 ;{ }^{\mathrm{C}}$ Scaling factor in Equations 2 and 3 equal to 1.0.

indicator of the thoracic fraction consistent with ISO $[26,27]$ recommendations for occupational or nonoccupational environments. Our estimates show less penetration of coarse particulate matter into the thoracic and gas exchange regions of the respiratory tract than current criteria. For typical breathing habits (i.e., not oral breathing), we would predict less than $20 \%$ penetration of $10 \mu \mathrm{m}$ particles into the thorax, whereas a $50 \%$ penetration of 10 $\mu \mathrm{m}$ is currently used in both occupational and nonoccupational criteria $[2,4,8,9]$. Recognizing that there are differences in the sources and chemical composition between ambient fine (nominal mean $\mathrm{d}_{\mathrm{a}} \leq 2.5 \mu \mathrm{m}$ ) and larger coarse PM, our finding may, in part, explain why causal relationships are observed between morbidity and mortality with short and long-term exposure to fine PM but not larger coarse PM (see Chapter 2 in Ref [28]).

There are two primary reasons for the dramatic difference between our estimates and the current criteria. First, the ACGIH [4] criteria considered all inspired air to enter via the oral airway which increases the penetration through the ET airways. With the exception of a laboratory setting, however, few individuals breathe exclusively through the mouth. This would make the breathing habits other than oral breathing preferable for the purposes of estimating actual exposures. Second, the ACGIH criteria are intentionally conservative (Figure 1) as the committee 
chose to afford extra protection by over representing the true penetration of particles into the lower respiratory tract. In Figure 2, we predicted a 50\% cut-point of $7.0 \mu \mathrm{m}$ for the conditions considered by the ACGIH, namely, an orally breathing adult male engaged in light exercise. Additionally, our predicted upper bound $95^{\text {th }}$ percentile for $50 \%$ cut-points during oral breathing corrected for inhalability in Table 7 are $\sim 10 \mu \mathrm{m}$. Thus, selection of 10 $\mu \mathrm{m}$ as having $50 \%$ penetration into the thorax was consistent with over representing the true penetration of particles into the lower respiratory tract of most individuals.

Route of breathing has a dramatic affect on particle delivery to the thoracic and respiratory regions since the deposition efficiency of the nasal passages greatly exceeds that of the oral pathway. Most subjects in the Niinimaa et al. [17] study, $87 \%$ (26 of 30), breathed through their nose until an activity level was reached when they switched to oronasal breathing. Thirteen percent (4 of 30) of the subjects, however, were oronasal breathers even at rest. These two subject groups are commonly referred to in the literature (e.g., see [12]) as "normal augmenters" and "mouth-breathers," respectively. Becquemin et al. [18] and Bennett et al. [19] showed that children tend to have a greater fraction of oral breathing than adults at rest and during exercise. Route of breathing may also vary between races; Bennett et al. [20] found that African-Americans and females had a greater nasal contribution to breathing during exercise than Caucasians and males. The abrupt change in route of breathing occurring in normal augmenters has not been observed by others. The gradual augmenter breathing habit based on Bennett et al. $[19,20]$ may be preferable to the normal augmenter in representing the general population. Chadha et al. [29] found that the majority (11 of 12) of patients with asthma or allergic rhinitis also breathe oronasally at rest. In healthy individuals, a small fraction (around 5\%) may breathe solely through the mouth [21]. Our estimates for gradual augmenters provide particle penetration fractions most typical of healthy populations. Our estimates for mouth-breathers may be more appropriate for patients with mild upper respiratory disease.

The ICRP model [12] appears to underestimate the penetration of particles through the ET airways of children. A $\mathrm{SF}_{\mathrm{t}}$ is applied in Equations 1-3 with the presumption that oral and nasal particle deposition increase with decreasing body size and increasing flow resistance.

For oral breathing on a mouthpiece, Bennett et al. [30] showed greater ET deposition in children than adults. This finding suggests that the application of a $\mathrm{SF}_{\mathrm{t}}$ of 1.26 in Eq 1 is appropriate for laryngeal deposition. However, for nasal breathing, Becquemin et al. [22] and Bennett et al. [19] showed less nasal deposition in children than in adults. These two studies, not considered in the ICRP model [12], suggest that it may be inappropriate to apply a $\mathrm{SF}_{\mathrm{t}}$ in Equations 2 and 3 for nasal deposition in children.
Lower nasal deposition of particles in children than adults means greater penetration of particles into the lower respiratory tract of children than adults. Accordingly, we conducted simulations for the child with the $\mathrm{SF}_{\mathrm{t}}$ in Equations 2 and 3 set equal to 1.0 in addition to the $\mathrm{SF}_{\mathrm{t}}$ of 1.26 recommended by ICRP [12]. The estimated nasal ET deposition efficiency of $2 \mu \mathrm{m}$ particles in the normal augmenter child during light exercise decreased from $68 \%$ to $48 \%$ when the $\mathrm{SF}_{\mathrm{t}}$ was decreased from 1.26 to 1.0. For comparison, under the same level of activity, the estimated ET deposition efficiency was $57-58 \%$ in the adult male and female. Decreasing the nasal deposition efficiency of the child relative to the ICRP model [12] increased the particle size estimated to have $50 \%$ penetration into the thoracic and respiratory regions (see Tables 5, 6, 7 and Figures 4 and 5 ). These estimates of larger 50\% cut points for childA than adults appear consistent with studies in children that were not incorporated into the ICRP model [12].

With the exception of Table 7, the thoracic and respirable fractions that we present are the amount of particles entering a specified respiratory tract region relative to the amount of particles entering the respiratory tract. In effect, we assumed $100 \%$ inhalability across the range of particle sizes $(0.5-20 \mu \mathrm{m})$ examined. We have opted on this convention since the inhalable fraction depends on factors not considered here such as wind speed and direction relative to the exposed individual. For recent reviews of the literature on particle inhalability, the reader is referred to Brown [31] and Millage et al. [32]. Adjusting our data for inhalability, shifts penetration curves to smaller particle sizes, but mainly only where there is a substantial contribution of oral breathing (see Table 7 vs. Table 5).

\section{Conclusion}

Our analyses show that occupation and non-occupational criteria for thoracic and respirable fractions overestimate the size of particles entering these regions. As already noted, penetration fractions for workplace criteria were chosen to afford extra protection by over-representing the true penetration of particles into regions of the respiratory tract [4]. However, accepted definitions for thoracic and respirable fractions speak specifically to particles that penetrate into these regions. As such, current occupational and non-occupational criteria may misinform practitioners with regard to the actual size of particles expected to reach regions of the respiratory tract during typical behavior. For instance, the current criteria suggest that $10 \mu \mathrm{m}$ particles (50\%) penetrate into the thorax, thus, leaving the expectation that observed health effects may be modulated by their deposition in either the upper or lower airways. However, we predict that about $20 \%$ or less of these $10 \mu \mathrm{m}$ particles would penetrate through the ET airways and into the lower respiratory tract. Our modifications to the ICRP model [12] related to breathing habit and nasal deposition 
in children reflect more recent data and provide consistent estimates of greater particle penetration into the thoracic and respiratory regions of children than adults. With those modifications, for median activities, we predict $50 \%$ cutpoints for $\mathrm{P}(\mathrm{ET})_{\text {avg }}$ at $\sim 3 \mu \mathrm{m}$ in adults and $\sim 5 \mu \mathrm{m}$ in children. The predicted $50 \%$ cut-points for $\mathrm{P}(\mathrm{TB})_{\text {avg }}$ are slightly less than $3 \mu \mathrm{m}$ in adults and slight greater than $4 \mu \mathrm{m}$ in children. Our estimates of particle penetration into the thoracic and respiratory regions of the respiratory tract should be useful in the design of experimental studies and interpretation of PM health effects evidence.

\section{Endnotes}

${ }^{a}$ More typically, the literature has defined this term in relation to the fraction of particles entering the gas-exchange region or the fraction penetrating through the tracheobronchial region, the ciliated airways, or conducting airways.

${ }^{\mathrm{b}}$ For completeness, other groups such as the British Medical Research Council offered size-selective sampling recommendations prior to the ACGIH. For a historical perspective, the reader is referred to Lippmann [33].

${ }^{\mathrm{c}}$ For accuracy it should be recognized that the sampler collection efficiency curves for EPA's PM $_{10}$ and ACGIH's thoracic fraction are different. The criteria are similar for particles smaller than the $50 \%$ cut-point at $10 \mu \mathrm{m}$. However, the curves diverge at about $12 \mu \mathrm{m}$, with a dramatic drop in collection efficiency (dictated by policy considerations) for EPA's $\mathrm{PM}_{10}$, and a more gradual decrease in collection efficiency for the ACGIH criterion.

${ }^{\mathrm{d}}$ The MPPD model typically outputs estimates of regional deposition for the entire respiratory cycle. For the purposes of this project, the software output was modified by the developers to provide inspiratory deposition fractions for particles in the ET and TB regions. Designating the ET and TB regions as separate compartments, the deposition efficiency in the TB region $\left(\eta_{\mathrm{TB}}\right)$ during inhalation was calculated from the MPPD output as $\mathrm{DF}_{\mathrm{TB}} /\left(1-\mathrm{DF}_{\mathrm{ET}}\right)$, where $\mathrm{DF}_{\mathrm{TB}}$ and $\mathrm{DF}_{\mathrm{ET}}$ are the deposition fractions of particles in the $\mathrm{TB}$ and ET region during inhalation, respectively. For more information about this model, the reader is referred to: http:// www.ara.com/products/mppd_capabilities.htm.

\section{Additional file}

Additional file 1: Comparison of respiratory particle fractions predicted by the MPPD and ICRP [12] models. In general, the ICRP [12] model predicts less particle penetration into the respiratory region than the MPPD model.

\section{Abbreviations}

ACGIH: American Conference of Governmental Industrial Hygienists; CEN: European Committee for Standardization; $\mathrm{d}_{\mathrm{a}}$ : Aerodynamic diameter; $\mathrm{DF}_{\mathrm{TB}}$ : Particle deposition fraction in the TB region during inhalation; $D_{E T}$ : Particle deposition fractions in the ET region during inhalation; EPA: U. S. Environmental Protection Agency; ET: Extrathoracic; f: Breathing frequency; $F_{m}$ : Fraction of breath passing through the mouth; FRC: Functional residual capacity; ICRP: International Commission on Radiological ProtectionISO International Organization for Standardization; MPPD: Multiple path particle dosimetry; NAAQS: National ambient air quality standard; $\eta_{\text {TB: }}$ Particle deposition efficiency in the tracheobronchial region; $\eta(E T)_{\text {larynx: }}$ Extrathoracic particle deposition efficiency in the larynx; $\eta\left(E_{1}\right)_{\text {nose: }}$ Extrathoracic particle deposition efficiency in anterior nasal region; $\eta\left(E_{2}\right)_{\text {nose: }}$ : Extrathoracic particle deposition efficiency in posterior nasal region; $\mathrm{P}(\mathrm{ET})$ : Particle penetration past the larynx and the thoracic fraction; $P(T B)$ : Particle penetration through the ciliated airways and the respirable fraction; PM: Particulate matter; $\mathrm{PM}_{2.5}$ : Particles with a nominal mean aerodynamic diameter $\leq 2.5 \mu \mathrm{m}$; $\mathrm{PM}_{10}$ : Indicator for thoracic coarse particles; $Q_{\text {nose: }}$ Inspiratory flow through the nose; $Q_{\text {total }}$ : Total inspiratory flow rate; $S_{t}$ : Scaling factor, ratio of trachea diameter in adult reference male to that of subject; t: Time spent engaged in specific activity; TB: Tracheobronchial; TSP: Total suspended particulate; URT: Upper respiratory tract volume; $V_{\text {daily: }}$ Total volume inspired in 24 hours; $V_{T}$ : Tidal volume

\section{Competing interests}

The authors have no competing interest.

\section{Authors' contributions}

JB conceived the project, coordinated and drafted the manuscript. TG contributed to defining the project's scope and drafting the manuscript. OP modified software for the purposes of this project to provide inspiratory deposition fractions for particles and participated in the interpretation of data. BA contributed to the methodology, participated in software development and drafting of the manuscript. All authors read and approved the final manuscript.

\section{Acknowledgments}

The authors thank Drs. Beverly Cohen (NYU), Martin Harper (NIOSH), Mort Lippmann (NYU), and Lindsay Wichers Stanek (U.S. EPA) for their helpful comments. TG was funded, in part, by a faculty appointment with the U.S. EPA through a program administered by Oak Ridge Institute for Science and Education (EPA-ORD/NCEA-RTP-2009-02). This document has been reviewed in accordance with U.S. Environmental Protection Agency policy and approved for publication. Mention of trade names or commercial products does not constitute endorsement or recommendation for use. The views expressed in this article are those of the authors and do not necessarily reflect the views or policies of the U.S. Environmental Protection Agency.

\section{Author details}

${ }^{1}$ National Center for Environmental Assessment, U.S. Environmental Protection Agency, MD B243-01, Research Triangle Park, Raleigh, NC 27711, USA. ${ }^{2}$ NYU School of Medicine, 57 Old Forge Road, Tuxedo, NY 10987, USA. ${ }^{3}$ Applied Research Associates, Inc, 801 N. Quincy St., Suite 700, Arlington, VA 22203, USA. ${ }^{4}$ Applied Research Associates, Inc, 8537 Six Forks Road., Suite 600, Raleigh, NC 27615, USA.

Received: 4 May 2012 Accepted: 3 February 2013

Published: 10 April 2013

\section{References}

1. Morgan WK: Industrial bronchitis. Br J Ind Med 1978, 35(4):285-291.

2. European Committee for Standardization (CEN): Workplace atmospheres-size fraction definitions for measurement of airborne particles (Report No. BS EN 481:1993). London, England: CEN, British Standards Institute; 1993. ISBN 0-580-221407.

3. American Conference of Governmental Industrial Hygienis (ACGIH): TLVs and BEIs: Based on the documentation of the threshold limit values for chemical substances and physical agents and biological exposure indices. Cincinnati, $\mathrm{OH}: \mathrm{ACGIH} ; 2005$.

4. American Conference of Governmental Industrial Hygienis (ACGIH): Particle sizeselective sampling in the workplace. Report of the ACGIH Technical Committee on Air Sampling Procedures. Cincinnati, OH: ACGIH; 1985. ISBN 0-936712-57-0.

5. Lippmann M: Regional deposition of particles in the human respiratory tract. In Handbook of Physiology - Reactions to Environmental Agents. Edited by Lee DHK, Falk HL, Murphy SD, Geiger SR, Bethesda MD. American Physiological Society; 1977:213-232 
6. Stahlhofen W, Gebhart J, Heyder J: Experimental determination of the regional deposition of aerosol particles in the human respiratory tract. Am Ind Hyg Assoc J 1980, 41:385-398.

7. Chan TL, Lippmann M: Experimental measurements and empirical modelling of the regional deposition of inhaled particles in humans. Am Ind Hyg Assoc J 1980, 41:399-409.

8. U.S. Environmental Protection Agency (U.S. EPA): Revisions to the national ambient air quality standards for particulate matter. Fed Regist 1987 52(July 1):24634-24669.

9. U.S. Environmental Protection Agency (U.S. EPA): National ambient air quality standards for particulate matter; final rule. Fed Regist 1997, 62(July 18):38652-38752

10. Miller FJ, Gardner JA, Graham JA, Lee RE, Willson WE, Bachmann JD: Size considerations for establishing a standard for inhalable particles. J Air Pollut Control Assoc 1979, 29:610-615.

11. International Organization for Standardization (ISO): Air quality - Sampling conventions for airborne particle deposition in the human respiratory system. Geneva, Switzerland: ISO 13138, First edition; 2012.

12. International Commission on Radiological Protection (ICRP): Human respiratory tract model for radiological protection: a report of a task group of the International Commission on Radiological Protection. Ann ICRP 1994, 24(1-3):1-482.

13. Bennett WD, Scheuch G, Zeman KL, Brown JS, Kim C, Heyder J, Stahlhofen W: Bronchial airway deposition and retention of particles in inhaled boluses: effect of anatomic dead space. J Appl Physiol 1998, 85:685-694.

14. Smith JR, Bailey MR, Etherington G, Shutt AL, Youngman MJ: Effect of particle size on slow particle clearance from the bronchial tree. Exp Lung Res 2008, 34:287-312.

15. Svartengren M, Falk R, Philipson K: Long-term clearance from small airways decreases with age. Eur Respir J 2005, 26:609-615.

16. Brochu P, Ducré-Robitaille JF, Brodeur J: Physiological Daily Inhalation Rates for Free-Living Individuals Aged 1 Month to 96 Years, Using Data from Doubly Labeled Water Measurements: A Proposal for Air Quality Criteria, Standard Calculations and Health Risk Assessment. Hum Ecol Risk Assess 2006, 12(4):675-701.

17. Niinimaa V, Cole P, Mintz S, Shephard RJ: Oronasal distribution of respiratory airflow. Respir Physiol 1981, 43(1):69-75.

18. Becquemin MM, Bertholon JF, Bouchikhi A, Malarbet JL, Roy M: Oronasal Ventilation Partitioning in Adults and Children: Effect on Aerosol Deposition in Airways. Radiat Prot Dosimetry 1999, 81:221-228.

19. Bennett WD, Zeman $\mathrm{KL}$, Jarabek AM: Nasal contribution to breathing and fine particle deposition in children versus adults. J Toxicol Environ Health A Curr Iss 2008, 71:227-237.

20. Bennett W, Zeman K, Jarabek A: Nasal contribution to breathing with exercise: effect of race and gender. J App/ Physiol 2003, 95:497-503.

21. James DS, Lambert WE, Mermier CM, Stidley CA, Chick TW, Samet JM: Oronasal distribution of ventilation at different ages. Arch Environ Health 1997, 52(2):118-123.

22. Becquemin $\mathrm{MH}$, Swift DL, Bouchikhi A, Roy M, Teillac A: Particle deposition and resistance in the noses of adults and children. Eur Respir J 1991 4:694-702.

23. Anjilvel S, Asgharian B: A multiple-path model of particle deposition in the rat lung. Fundam Appl Toxicol 1995, 28:41-50.

24. Yeh HC, Schum GM: Models of human lung airways and their application to inhaled particle deposition. Bull Math Biol 1980, 42:461-480.

25. De Winter-Sorkina R, Cassee FR: From concentration to dose: Factors influencing airborne particulate matter deposition in humans and rats. Bilthoven, The Netherlands: National Institute of Public Health and the Environment RIVM, report 650010031/2002; 2002. Available: http://www rivm.nl/bibliotheek/rapporten/650010031.html (accessed 7 Jan 2011).

26. International Organization for Standardization (ISO): Size definitions for particle sampling: recommendations of ad hoc working group appointed by Committee TC 146 of the International Standards Organization. Am Ind Hyg Assoc J 1981, 42(5):A64-A68.

27. International Organization for Standardization (ISO): Air quality - Particle size fraction definitions for health related sampling. Geneva, Switzerland: Technical Report ISO/TR; 1983:7708-1983.

28. U.S. Environmental Protection Agency (U.S. EPA): Integrated Science Assessment for Particulate Matter. Research Triangle Park, NC: National Center for Environmental Assessment, Office of Research and Development, U.S. EPA; 2009. EPA/600/R-08/139F.
29. Chadha TS, Birch S, Sacker MA: Oronasal distribution of ventilation during exercise in normal subjects and patients with asthma and rhinitis. Chest 1987, 92(6):1037-1041.

30. Bennett WD, Zeman KL, Kang CW, Schechter MS: Extrathoracic deposition of inhaled, coarse particles $(4.5 \mu \mathrm{m})$ in children vs. adults. In Inhaled particles VIII: proceedings of an international symposium on inhaled particles organized by the British Occupational Hygiene Society; August 1996, Ann Occup Hyg. Edited by Cherry N, Ogden T. Cambridge, UK: 1997:497-502. 41(suppl. 1)

31. Brown JS: Particle inhalability at low wind speeds. Inhal Toxicol 2005 17(14):831-837.

32. Millage KK, Bergman J, Asgharian B, McClellan G: A review of inhalability fraction models: discussion and recommendations. Inhal Toxicol 2010, 22(2):151-159

33. Lippmann M: Size-selective health hazard sampling. In Air Sampling Instruments for evaluation of atmospheric contaminants, $9^{\text {th }}$ ed. Edited by Choen BS, McCammon CS Jr. Cincinnati, OH: ACGIH Worldwide; 2001. ISBN 1-882417-39-9.

doi:10.1186/1743-8977-10-12

Cite this article as: Brown et al:: Thoracic and respirable particle definitions for human health risk assessment. Particle and Fibre Toxicology 2013 10:12

\section{Submit your next manuscript to BioMed Central and take full advantage of:}

- Convenient online submission

- Thorough peer review

- No space constraints or color figure charges

- Immediate publication on acceptance

- Inclusion in PubMed, CAS, Scopus and Google Scholar

- Research which is freely available for redistribution

Submit your manuscript at www.biomedcentral.com/submit
C BioMed Central 